\title{
To study the effectiveness of indigenous bubble CPAP in management of respiratory distress in newborns
}

\author{
Jain $\mathbf{H}^{1}$, Arya $\mathbf{S}^{2}$, Mandloi $\mathbf{R}^{3}$, Menon $\mathrm{S}^{4}$ \\ ${ }^{1}$ Dr Hemant Jain, Professor, ${ }^{2}$ Dr Sunil Arya, Assistant Professor, ${ }^{3}$ Dr Rashika Mandloi, P.G Student, ${ }^{4}$ Dr Suresh Menon, \\ P.G Student. All are affiliated with Department of Pediatrics, M.G.M. Medical College, Indore ( MP)
}

Address for Correspondence: Dr Sunil Arya, Email: drsunilarya22@gmail.com

\begin{abstract}
Background: CPAP has become a useful in management of respiratory distress, especially in preterms. CPAP delivers a continuous distending pressure via the neonates pharynx to the upper and lower airways. The main indication for use of CPAP is RDS. Aim of study: To study the effectiveness of indigenous bubble CPAP in management of respiratory distress in newborn and to determine its outcome. Setting: Department of Pediatrics, MGM Medical College and MY Hospital, Indore during the period February-July 2005. Design: Prospective Observational Study. Method: This study was carried out on inborn neonates in the NICU of MY Hospital over a period of six months. Matched controls were taken from admissions during previous four months. It included the newborns developing respiratory distress with grunting and chest retractions within 6 hours of birth whose severity was measured by Silverman Anderson Score and oxygen saturation.Neonates with increasing Silverman Anderson Score or Oxygen saturation falling below $85 \%$ were taken on CPAP and their outcome studied. Result: There were 42 RDS cases in the study group of which 28 survived and 14 died. Indigenous BUBBLE CPAP was beneficial in managing babies with RDS. Conclusion: Indigenous BUBBLE CPAP is an effective and non-invasive way to provide ventilation in a setup with limited resources. It can be used to manage respiratory distress due to RDS, congenital pneumonia \& MAS. It resulted in significant reduction in mortality but prognosis was bad in those who required CPAP $>8 \mathrm{~cm} \mathrm{H}_{2} \mathrm{O}$.
\end{abstract}

Key words: CPAP: continous positive airway pressure, RDS:respiratory distress syndrome, MAS:Meconium aspiration syndrome

\section{Introduction}

Continuous positive airway pressure (CPAP) is anon invasive method for applying a constant distending pressure level during inhalation and exhalation to support spontaneously breathing newborns with lung disease [1]. The main indication for use of CPAP is respiratory distress syndrome. Lack of awareness and suboptimal practice of antenatal steroids result in frequent RDS in premature babies. Early use of CPAP will be low-cost, simple and noninvasive option for a country like India, where most places cannot provide invasive ventilation. With the cost of surfactant likely to decrease markedly, use of early CPAP in conjunction with surfactant, when indicated can prove to be a boon in future for preterm in India. The present study was undertaken to determine the effectiveness of indigenous

Manuscript received: $14^{\text {th }}$ March 2016 Reviewed: $27^{\text {th }}$ March 2016

Author Corrected; $10^{\text {th }}$ April 2016

Accepted for Publication: $23^{\text {rd }}$ April 2016
BUBBLE CPAP as a non-invasive approach for managing respiratory distress in newborns in a setup with limited resources

\section{Method}

This study was carried out on inborn neonates in the NICU of Maharaja Yashwant Rao Hospital over a period of six months. Matched controls taken from cases admitted to the same NICU in the previous four month period.

\section{Inclusion criteria}

1. Newborns developing respiratory distress with grunting and chest retractions within 6 hours of birth.

2. All newborns were above 1000 grams of birth weight.

\section{Exclusion Criteria.}

1. Any congenital malformations.

2. Onset of respiratory distress after 6 hours of birth. 
3. Birth weight less than 1000 grams.

4. Newborns without grunting respiration.

Severity of respiratory distress was measured by Silverman Anderson score [2] and oxygen saturation. Newborns having respiratory distress with Silverman Anderson Score of 3 or more than 3 were started on oxygen inhalation and :

A) If not improving.

B) Oxygen saturation falling less than $85 \%$.

C) Increasing Silverman Anderson Score were taken on CPAP and their outcome studied. ABG was not done. Under the study protocol, newborns with respiratory distress fulfilling the inclusion criteria were started on CPAP. An indigenous BUBBLE CPAP apparatus was assembled. The indigenous CPAP assembly is a simple and least expensive NASAL BUBBLE CPAP SYSTEM.

\section{Equipment required:}

1. Container Bottle with lid, filled with normal saline with $0.25 \%$ acetic acid to a depth of $10 \mathrm{~cm} \mathrm{H} 2 \mathrm{O}$.

2. Column to fit through the lid of this container.

3. Two nasal catheters.

4. Two 3 way valves.

5. Two intravenous sets.

6. Oxygen source.

\section{Observations}

Table 1: Survival among various etiologies on CPAP.

\begin{tabular}{|l|l|l|l|l|}
\hline & RDS & Congenital Pneumonia & MAS & Total \\
\hline Total & $42(75 \%)$ & $9(16 \%)$ & $5(8 \%)$ & 56 \\
\hline Survived & $28(66.67 \%)$ & $7(77.78 \%)$ & $4(80 \%)$ & 39 \\
\hline Deaths & $14(33.3 \%)$ & $2(22.2 \%)$ & $1(20 \%)$ & 17 \\
\hline
\end{tabular}

$75 \%$ of newborns had RDS followed by congenital pneumonia in $16.07 \% .66 .7 \%$ of the babies with RDS put on CPAP survived.

Table 2: Distribution of deaths according to the gestational age.

\begin{tabular}{|l|l|l|l|}
\hline Gestational age (weeks) & Number & Deaths & survivals \\
\hline $\mathbf{3 0 - 3 2}$ & $18(32.14 \%)$ & $11(64.29 \%)$ & $7(35.71 \%)$ \\
\hline $\mathbf{3 3 - 3 5}$ & $24(42.86 \%)$ & $5(20.83 \%)$ & $19(79.16 \%)$ \\
\hline$>35$ & $14(25 \%)$ & 0 & 0 \\
\hline
\end{tabular}

$21.4 \%$ of the babies were term and $78.6 \%$ were preterm. $64.29 \%$ of the deaths in babies with RDS was in the gestational age group of 30-32 weeks, whereas $20.83 \%$ of the deaths were between 33-35 weeks.

Table 3: Distribution of total cases of RDS according to weight.

\begin{tabular}{|l|l|l|}
\hline Weight (grams) & Number & survival \\
\hline $\mathbf{1 0 0 0 - 1 2 5 0}$ & 10 & $5(23.81 \%)$ \\
\hline $\mathbf{1 2 5 1 - 1 5 0 0}$ & 22 & $15(68.18 \%)$ \\
\hline$>1500$ & 10 & $8(80 \%)$ \\
\hline
\end{tabular}


$50 \%$ (10) of the babies with RDS survived in the weight range of 1000-1250 grams, whereas the weight range of 1251 1500 grams showed a better survival of $68.18 \%$ (22) and >1500 grams had a even better survival of $80 \%$ (10).

Table 4: Distribution of cases of RDS survivors in relation to the initiation of CPAP (in hrs).

\begin{tabular}{|l|l|l|l|l|l|l|l|}
\hline Initiation of CPAP (hrs) & $\mathbf{1}$ & $\mathbf{2}$ & $\mathbf{3}$ & $\mathbf{4}$ & $\mathbf{5}$ & $\mathbf{6}$ & \\
\hline Number & 4 & 6 & 10 & 3 & 4 & 1 & 28 \\
\hline Percentage & $14.19 \%$ & $21.42 \%$ & $35.71 \%$ & $10.71 \%$ & $14.28 \%$ & $3.57 \%$ & $100 \%$ \\
\hline
\end{tabular}

- The mean time of starting CPAP among survivors of RDS was 3 hrs+(range 1-6 hrs).

- The mean time of starting CPAP among deaths in RDS was 2.5 hrs+_ (range 1-5 hrs).

- The mean duration of CPAP among survivors was $39.6 \mathrm{hrs} \pm$ (range 12-96 hrs)

Table 5: Comparing mortality of study cases and controls.

\begin{tabular}{|l|l|l|l|l|l|l|l|}
\hline & Total & RDS & Cong. Pneumonia & \multicolumn{2}{|c|}{ MAS } \\
\cline { 3 - 8 } & & Total & Mortality & total & mortality & Total & Mortality \\
\hline Study cases & 56 & 42 & $14(33.34 \%)$ & 9 & $2(22.2 \%)$ & 5 & $1(20 \%)$ \\
\hline Controls & 41 & 32 & $17(53.1 \%)$ & 4 & $2(50 \%)$ & 5 & $2(40 \%)$ \\
\hline
\end{tabular}

\section{Discussion}

This was a prospective study done in the NICU of M.Y. Hospital, Indore. The period of study was between February 2005 and July 2005. A total of 56 cases with respiratory distress fulfilling the inclusion criteria were enrolled during this period. The outcome of these babies on indigenous BUBBLE CPAP was studied. The results were compared with the babies with respiratory distress, who were managed in the same setting in the preceding 4 months without CPAP. These babies served as the control group. Gestational age wise and birth weight wise categorization of babies was evenly matched in the two groups. The etiology of respiratory distress was similar in both the groups.

There were 42 cases of RDS in the study group. Out of them $28(66.7 \%)$ survived and 14 died. While in a study by Gregory GA et al [3] they have taken 20 cases of RDS out of which 16 survived $(80 \%)$. Out of total 56 cases, 30 were males and 26 females.

The mortality of male babies on CPAP was higher $(46.66 \%)$ in comparison to females $(11.54 \%)$ in the study group though the sex distribution of cases taken was similar. Amongst controls 53.66\% (22) were males and $46.34 \%$ (19) were female. The distribution of mortality between males $(52.38 \%)$ and females $(47.62 \%)$ were comparable in the control group. In our study, $80.49 \%$ were preterm and $19.51 \%$ were term. Out of these $31.71 \%$ (13) were between $30-32$ weeks, $39.02 \%$ (16) between $33-35$ weeks and $29.27 \%$ (12) more than 35 weeks. Ventilation has a major role in the management of respiratory distress (RDS) in the newborn babies as studied by Singh M et.al [4] Singh $\mathrm{M}$ et. al [5] and P.P. maiya et al [6]. But it requires costly equipments and is often invasive. Noninvasive ventilation in the form of CPAP has increasingly come to play a significant role in the management of respiratory distress in newborns. In a country like India where most places lack facilities, an alternative indigenous way to provide CPAP in a set up with limited resources was explored. This study was aimed at finding out whether indigenously assembled BUBBLE CPAP was effective in the management of respiratory distress in the newborn and to compare the outcome of these babies with that of the babies managed previously without CPAP. In our study babies with MAS showed survival rate of $80 \%$ with CPAP same as study done by maiya PP et al [7] also observed CPAP has a role in MAS. Early nasal CPAP was found to reduce the need for subsequent intubations and mechanical ventilation by roughly $50 \%$ without affecting overall mortality or the incidence of chronic lung disease [8].

In this study, the mean time of starting CPAP among survivors of RDS was $3 \mathrm{hrs}$ (range 1-6hrs). There are various other studies which show that infants who could be managed on nasal CPAP alone had a lower mortality and a reduced incidence of chronic lung disease and severe intracranial hemorrhage. All of these studies suffer from the lack of randomized group of control infants, and many of the outcomes may reflect other changes in practice or differences in underlying disease severity. However, their results are intriguing and call 
for randomized control trials to determine the safety and utility of early nasal CPAP. Another study by D Millar, H. Kirpilani [9] showed benefits of non invasive ventilation. CPAP has been extensively used in the treatment of RDS which is an excellent indication for CPAP. The survival rates reported are $67-83 \%$. In our study 28 out of the 42 babies with RDS survived on CPAP. This compares favorably with immediately previous four months figures of $46.9 \%$ survival of the 32 babies with RDS. According to the Cochrane review [10], use of CPAP was associated with lower rates of failed treatment by about $30 \%$, overall mortality by $50 \%$, and mortality in babies with birth weight above 1500 grams by as much as $75 \%$. The Silverman Anderson Score was used to assess the severity of respiratory distress. The babies with RDS who expired had a high Silverman Score compared to the babies who survived. $85.71 \%$ of babies with RDS who survived had a Silverman Anderson Score of 5 or 6. This is in contrast to the fact that $78.57 \%$ of babies with RDS who died had a Silverman Anderson Score of 8 or above. In an interesting study from South Africa have demonstrated that nasal CPAP even in the absence of surfactant replacement therapy increases the survival rate of extremely immature babies with moderate to severe underlying RDS.

\section{Conclusion}

The survival of babies on indigenous BUBBLE CPAP was significantly higher than that of those managed without CPAP. An indigenously assembled BUBBLE CPAP is an effective and non-invasive way to provide ventilation in a setup with limited resources.

\section{Source of Support: Nil, Conflict of Interest: None Permission of IRB: Yes}

\section{References}

1. Di Blasi RM. Nasal continuous positive airway pressure for the respiratory care of the newborn infant. Respir care 2009 sep; 54(9):1209-35.
2. Silverman, W. and Anderson, D: Pediatrics 17:1, 1956. Copyright American Academy of Pediatrics.

3. Gregory GA, Kitterman JA, Phibbs RH, Tooley WH, Hamilton WK. Treatment of idiopathic respiratorydistress syndrome with continuous positive airway pressure. N Engl J Med. 1971 Jun 17;284(24):1333-40..

4. Singh M, Deorari AK, Paul VK, Mittal M, Shankar $\mathrm{S}$, Munshi U, et al. Three year experience with neonatal ventilation from a tertiary care hospital in Delhi. ndian Pediatr. 1993 Jun;30(6):783-9.

5. Singh M, Deorari AK, Agarwal R, Paul VK. Assisted ventilation for hyaline membrane disease. Indian Pediatr. 1995 Dec;32(12):1267-74.

6. P.P. Maiya, D. Viswanath, S. Hegde, T.P. Srinivas, Shivprasad, C.C. Shantala, P. Umakumaran, Naveen B. And R.K. Hegde, Mechanical ventilation of new borns: experience from a level-II NICU 1275 Indian Pediatrics 1995, 32:1-12.

7. Maiya PP, Vishwanath D, Bhat S, Karthik NN, Shenoi A, Joseph T. Neonatal Ventilation. 15th Annual Convention of the National Neonatology Forum, Patna, 1995.

8. Millar D, Kirpalani H. Benefits of noninvasive ventilation. Indian Pediatr. 2004 Oct;41(10):1008-17.

9. Gittermann et al. 1997. Pediatric and neonatal mechanical ventilation : from basics to clinical practice, page no. 397.

10. Ho JJ, Henderson-Smart DJ, Davis PG. Early versus delayed initiation of continuous distending pressure for respiratory distress syndrome in preterm infants. Cochrane Database Syst Rev. 2002; (2): CD002975. Oxford: Update Software Ltd.

\section{How to cite this article?}

Jain H, Arya S, Mandloi R, Menon S. To study the effectiveness of indigenous bubble CPAP in management of respiratory distress in newborns.Int J Pediatr Res 2016;3(5):293-296.doi:10.17511/ijpr.2016.i05.04 